\title{
Conjugate Spun of Polyethylene Terephthalate Resin Modified with 1,4-Cyclohexanedimethanol
}

\author{
Ho-Ju Bang, Hak-Yong Kim, ${ }^{*}$ Fan-Long Jin, ${ }^{\dagger}$ Je-Wan Woo,${ }^{\S}$ and Soo-Jin Park ${ }^{\ddagger}, *$ \\ Department of Textile Engineering, Chonbuk National University, Chonju 560-756, Korea. *E-mail: khy@chonbuk.ac.kr \\ ${ }^{\dagger}$ School of Chemical and Materials Engineering, Jilin Institute of Chemical Technology, Jilin City 132022, P. R. China \\ ${ }^{\ddagger}$ Department of Chemistry, Inha University, Nam-gu, Incheon 402-751, Korea. *E-mail: sjpark@inha.ac.kr \\ ${ }^{\S}$ Department of Industrial Chemistry, Sangmyung University, Seoul 110-743, Korea \\ Received January 6, 2010, Accepted December 6, 2010
}

\begin{abstract}
In this study, conjugate fibers were prepared from 1,4-cyclohexanedimethanol-modified polyethylene terephthalate (PET) resin using side by side conjugate spinning, sea-island type conjugate spinning, and split type conjugate spinning methods, and the properties of the conjugate fibers were investigated via several techniques. When viscosity increased, the tenacity of side by side conjugate fibers was increased, whereas elongation decreased. The sea-island conjugate fibers showed lower weight loss and surface color difference $(\mathrm{K} / \mathrm{S})$ values relative to that of regular PET fibers at the same conditions. The SEM results indicate that orange type spilt readily produced at a temperature range of $120-140{ }^{\circ} \mathrm{C}$.
\end{abstract}

Key Words: 1,4-Cyclohexanedimethanol, Polyethylene terephthalate, Conjugate fiber, Tenacity, Elongation

\section{Introduction}

Linear polyethylene terephthalate (PET) fibers are synthesized from ethylene glycol and terephtalic acid. PET fibers have excellent basic properties, including good mechanical properties and chemical resistance, antibiosis, easy of care, and form stability. ${ }^{1,2}$ Recently, PET fibers have been prepared using new radiation methods and post-processing techniques. Among these methods, modification of PET (M-PET) at the PET polymerization stage to obtain various characteristics is one of the representative methods. This M-PET can be radiated alone, but is mainly radiated with regular PET and applied as PET/M-PET conjugate fibers. These superfine fibers have excellent luster, texture, and appearance, characteristics that are extensively required in upscale textile goods, drainage textile goods, hygroscopicity knitwear, cleaners, and square luck. ${ }^{3-6}$

The preparation methods of superfine fibers can be devided into direct spinning and conjugate spinning. Direct spinning is a method of spinning a single ingredient of the filament, and thereby producing a uniform product of the physical properties by fusing, wet process, and dry radiation. However, direct spinning is a complicated processs, and bad radiation work characteristic. Conjugate spinning, meaanwhile requires additional processes, such as process division or gushing. Conjugate radiation can be divided into two kinds, sectional type and gushing style, according to polymerization composition and sectional form. ${ }^{7}$

PET/M-PET conjugate fibers have been used to prepare new fabrics for artificial leather. Radiation of PET/M-PET conjugate fibers does not require the use of organic solvents, and the fibers are prepared from weight loss by alkali hydrolysis. Thus, this process significsntly affects the physical properties and dyeing characteristics of the final product, including weight loss processing of regular PET. ${ }^{8}$

In a previous work, we synthesized 1,4-cyclohexanedimethanol (CHDM)-modified PET resin (Co-PET) and investigated the properties of fibers spun from Co-PET. ${ }^{9}$ In this study, con- jugate fibers were prepared from Co-PET using side by side conjugate spinning, sea-island type conjugate spinning, and split type conjugate spinning methods. Properties such as alkali weight loss and dyeing characteristics of the conjugate fibers were characterized via several techniques.

\section{Experimental}

Materials. Polyethylene terephthalate (PET), terephtalic acid (TPA), 1,4-cyclohexanedimethanol (CHDM), and ethylene glycol (EG) used in this study were purchased from Aldrich. The PET has an average molecular weight of $20000 \mathrm{~g} / \mathrm{mol}$. Antimony trioxide and trimethyl phosphate were used as a catalyst and antioxidant, respectively, and supplied by Aldrich. CHDMmodified PET resin (Co-PET) was synthesized according to a method reported in a previous work, and the structure of Co-PET is shown in Figure 1.

Synthesis of Co-PET. PET oligomer $(5014 \mathrm{~g})$ was added to a $15 \mathrm{~L}$ reactor equipped with a mechanical stirrer, thermometer sensor, and reflux condenser. The PET oligomer was heated to $70{ }^{\circ} \mathrm{C}$ and then terephtalic acid (288 g), CHDM (250 g), and ethylene glycol $(270 \mathrm{~g})$ were added to the reactor. The mixtures were gradually heated to $250{ }^{\circ} \mathrm{C}$ and reacted for $1 \mathrm{~h}$. Antimony trioxide $(3 \mathrm{~g})$ and trimethyl phosphate $(1.5 \mathrm{~g})$ were added into mixtures. The mixtures were gradually heated to $280{ }^{\circ} \mathrm{C}$ and reacted under vacuum of 0.5 torr for $1 \mathrm{~h}$. Finally, chip type melting materials were obtained (yield: 90.5\%). Mn: $16500 \mathrm{~g} / \mathrm{mol}$. FT-IR (KBr; $\left.v, \mathrm{~cm}^{-1}\right): 2970(\mathrm{CH}), 1725(\mathrm{C}=\mathrm{O}), 1638(\mathrm{C}=\mathrm{C})$, $1620(\mathrm{C}=\mathrm{C}), 1190(\mathrm{C}-\mathrm{O}-\mathrm{C}), 1062(\mathrm{C}-\mathrm{H}), 988(\mathrm{CH}) .{ }^{1} \mathrm{H}$ NMR $\left(\mathrm{CDCl}_{3}\right)$ 1.32-2.24 ppm $\left(\mathrm{CH}_{2}\right), 4.24-4.72 \mathrm{ppm}\left(\mathrm{OCH}_{2} \mathrm{CH}_{2} \mathrm{O}\right)$, $7.61-8.76 \mathrm{ppm}$ (aromatic ring).

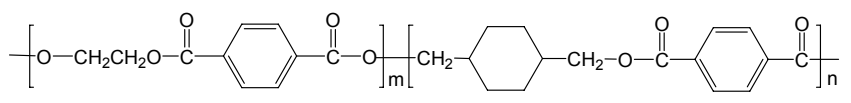

Figure 1. Chemical structure of CHDM-modified copolyester. 
Table 1. Experimental condition for manufacturing side by side conjugate fibers

\begin{tabular}{|c|c|c|c|c|c|}
\hline \multirow{2}{*}{ Sample } & \multicolumn{2}{|c|}{ Yarn component (IV) } & \multirow{2}{*}{ Spinning temperature $\left({ }^{\circ} \mathrm{C}\right)$} & \multirow{2}{*}{ Drawing temperature $\left({ }^{\circ} \mathrm{C}\right)$} & \multirow{2}{*}{ Drawing ratio } \\
\hline & A & $\mathrm{B}$ & & & \\
\hline 60SSY82 & 0.60 & 0.55 & \multirow{5}{*}{$\begin{array}{l}\text { A: } 285 \\
\text { B: } 275\end{array}$} & 82 & 3.426 \\
\hline 60SSY92 & 0.60 & 0.55 & & 92 & 3.426 \\
\hline 64SSY82 & 0.64 & 0.55 & & 82 & 3.254 \\
\hline 64SSY92 & 0.64 & 0.55 & & 92 & 3.254 \\
\hline 64SD82 & 0.64 & 0.55 & & 82 & 3.254 \\
\hline
\end{tabular}

Table 2. Properties of island component modified by different CHDM content

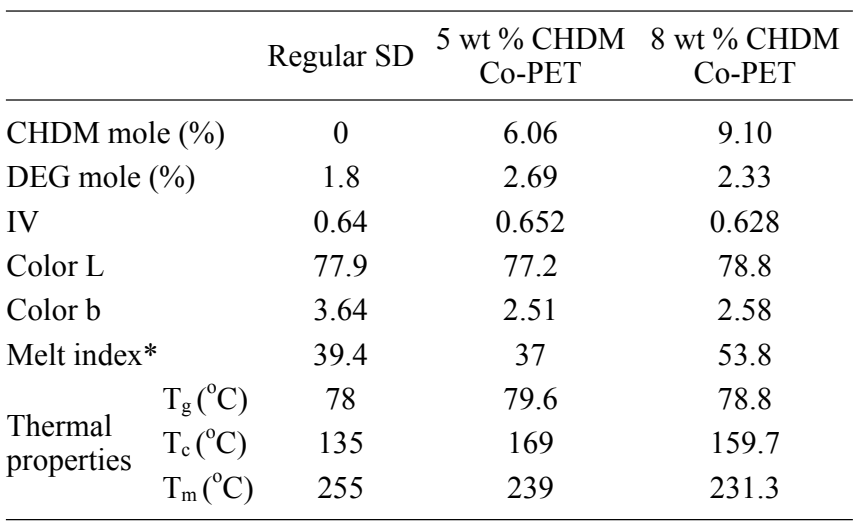

*measured at $280{ }^{\circ} \mathrm{C}$.

Side by Side Conjugate Spinning. Side by side conjugate fibers were prepared using the UDY-FDY method. $5 \mathrm{wt} \%$ CHDM- modified Co-PET and semi dull (SD) were used as high and low viscosity ingredient. The radiation conditions are shown in Table 1.

Sea-island Type Conjugate Spinning. Co-PET was melted and removed after at alkali treatment process, and superfine fibers of $0.07 \sim 0.04 \mathrm{~d} /$ f were formed. In order to investigate the basic physical properties and shrinkage ratio of sea-island type superfine fibers, elongation expense was 2.607 and 2.707, first $\mathrm{G} / \mathrm{R}$ temperatures were 90,95 , and $100^{\circ} \mathrm{C}$, and secondary $\mathrm{G} / \mathrm{R}$ temperatures were 120,125 , and $130{ }^{\circ} \mathrm{C}$.

Split Type Conjugate Spinning. Table 2 shows the properties of island components modified by different CHDM content. The fibers were prepared using CHDM-modified Co-PET resin as an island component at a spinning speed of $1100 \mathrm{~m} / \mathrm{min}$. Other spinning conditions are listed in Table 3.

Melting Temperature and Glass Transition Temperature Measurements. The melting temperature and glass transition temperature of the samples were measured with a differential scanning calorimeter (Perkin-Elmer DSC-7) at a heating rate of $10{ }^{\circ} \mathrm{C} / \mathrm{min}$ from 30 to $350{ }^{\circ} \mathrm{C}$ under a nitrogen atmosphere.

Alkali Weight Loss Measurements. 5\% alkali aqueous solution was heated to its boiling point, and then a round sample was added into this solution. The solution was stirred and then washed with distilled water, and finally dried in a vaccuum oven. The weight loss of the sample was calculated by the following equation.
Table 3. Experimental conditions for preparing orange split type conjugate fibers

\begin{tabular}{|c|c|c|c|c|}
\hline & & $\mathrm{T}-1$ & $\mathrm{~T}-2$ & $\mathrm{~T}-3$ \\
\hline \multirow{2}{*}{$\begin{array}{c}\text { Component } \\
\text { (composition \%) }\end{array}$} & Sea & WSD-X (30) & WSD-X (30) & WSD-X (30) \\
\hline & Island & $\mathrm{SD}(70)$ & $\begin{array}{c}\text { CHDM } 5 \\
\text { wt \% (70) }\end{array}$ & $\begin{array}{l}\text { CHDM 8 } \\
\text { wt \% (70) }\end{array}$ \\
\hline \multirow{2}{*}{ PT $\left({ }^{\circ} \mathrm{C}\right)$} & Sea & 282 & 287.5 & 287.5 \\
\hline & Island & 290 & 280 & 283.5 \\
\hline \multicolumn{2}{|c|}{ Draw ratio } & 3.106 & 3.106 & 3.106 \\
\hline \multicolumn{2}{|c|}{ Temperature $\left({ }^{\circ} \mathrm{C}\right)$} & $75 / 75$ & $75 / 75$ & $75 / 75$ \\
\hline \multicolumn{2}{|l|}{ CDS } & 70 & 70 & 70 \\
\hline
\end{tabular}

$$
\text { Weight loss }(\%)=\frac{\left(W_{0}-W_{1}\right)}{W_{0}}
$$

where $W_{0}$ and $W_{1}$ are the weight of the sample before and after alkali treatment, respectively.

Inherent Viscosity Measurements. The specimens were dissolved in phenol/tetrachloroethane (60/40 weight ratio) mixed solvent at $130{ }^{\circ} \mathrm{C}$. The concentration was measured using an Ubbelohde viscosimeter $1 \mathrm{C}$ type at $30^{\circ} \mathrm{C}$, and inherent viscosity ([ๆ]) was calculated from the Solomon-Ciuta equation. ${ }^{10}$

$$
[\eta]=\frac{1}{c}\left[2\left(\eta_{s p}-\ln \eta_{r}\right)\right]^{\frac{1}{2}}
$$

where $\eta_{s p}$ is the specific viscosity, $\eta_{r}$ is the relative viscosity, and $c$ is the concentration of polymer solution.

Shrinkage Measurements. The fibers were configured in a hoop form and hung on a clip of $0.7 \mathrm{~g}$, and the length $\left(\mathrm{L}_{1}\right)$ of the hoop was then measured. The hoop was added into a glass tube in a damp contraction percentage measurement device and dipped at $100 \pm 1{ }^{\circ} \mathrm{C}$ for $30 \mathrm{~min}$. Two hours after removing the hoot from tube, the length $\left(\mathrm{L}_{2}\right)$ of the hoop was measured. The shrinkage was calculated according to the following equation.

$$
\text { Wet shrinkage ratio }(\%)=\frac{L_{1}-L_{2}}{L_{1}} \times 100
$$

Strength and Elongation Measurements. A tensile test was conducted using an Instron mechanical tester (Fafegraph-M and 
(a)

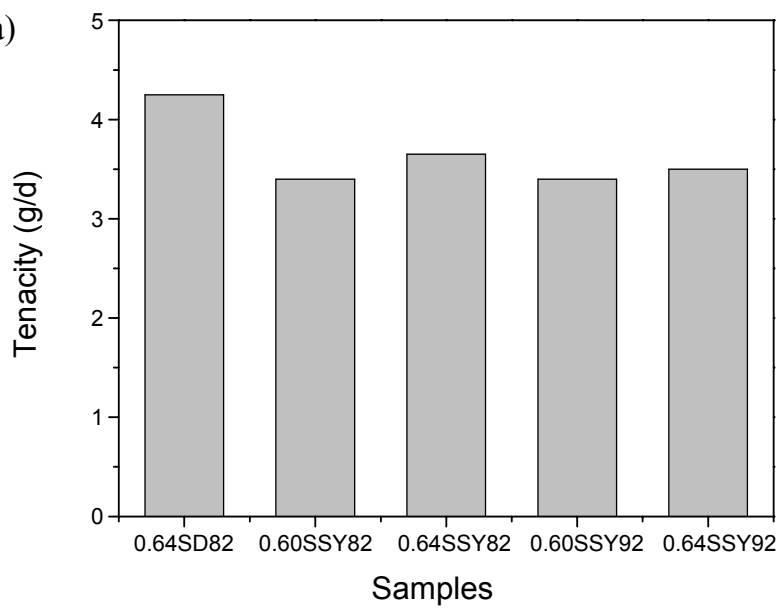

(b)

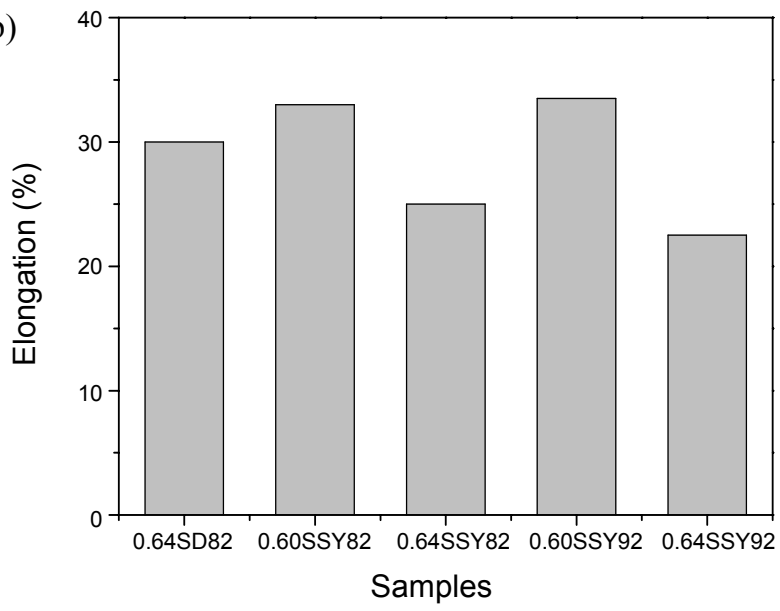

Figure 2. Tenacity (a) and elongation (b) of side by side conjugate fibers prepared from different experimental conditions.

Textecho Co., Germany) at a temperature of $25^{\circ} \mathrm{C}$ and relative humidity of $65 \%$. The specimen length was $100 \mathrm{~mm}$ and the tensile speed was $200 \mathrm{~mm} / \mathrm{min}$. All mechanical property values were obtained by averaging ten experimental values.

Evaluation of Dyeing Characteristics. To evaluate the dyeing quality, Lumacron Black SE-3G was used as a dye. $2 \%$ dye (fiber weight was used as a base) was diluted to a liquid ratio of 1:20. The samples were dyed at $100{ }^{\circ} \mathrm{C}$ for $30 \mathrm{~min}$ and then washed with distilled water at $80{ }^{\circ} \mathrm{C}$ for $10 \mathrm{~min}$. The surface color difference $(K / S)$ of the samples was calculated by using equation (4).

$$
\frac{K}{S}=\frac{(1-R)^{2}}{2 R}
$$

where $R$ is reflexibility, $K$ is the light absorption, and $S$ is the scattered coefficient at a wavelength.

\section{Results and Discussion}

Side by Side Conjugate Spinning. Side by side conjugate fibers were prepared according to the radiation conditions, as shown in Table 1 . The side by side conjugate fiber is a superfine

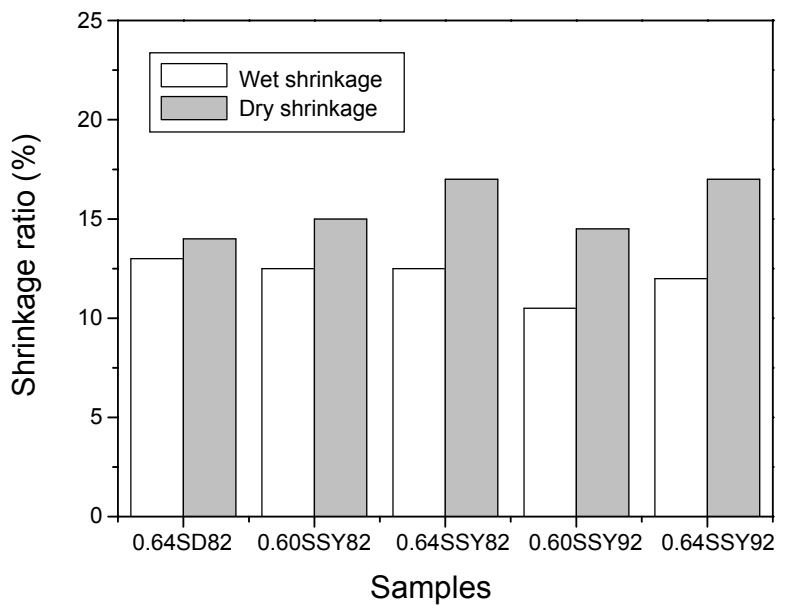

Figure 3. Shrinkage ratio of side by side conjugate fibers prepared from different experimental conditions.

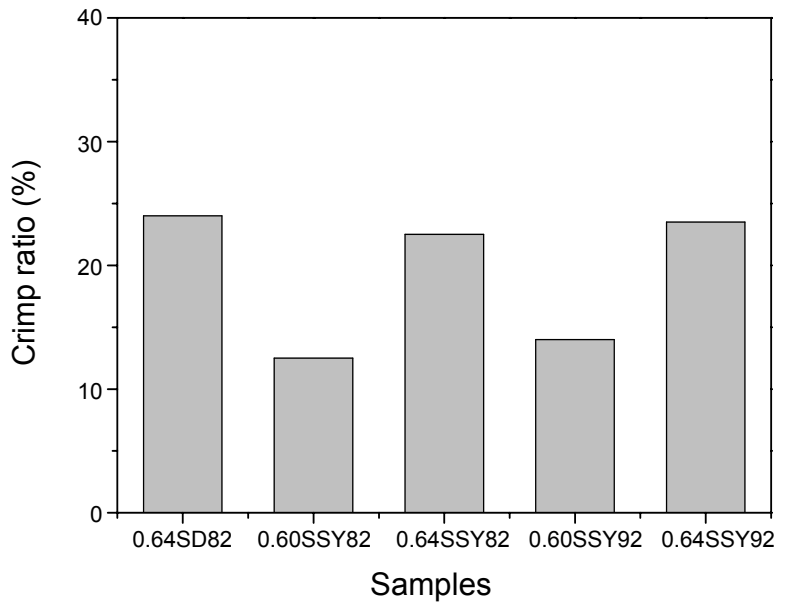

Figure 4. Crimp ratio of side by side conjugate fibers prepared from different experimental conditions.

fiber wherein a circular section is invided with a parallel straight line. The properties of the side by side conjugate fibers were investigated by measurements of the tenacity and elongation.

Figure 2 shows the tenacity and elongation of fibers prepared under different experimental conditions. When the viscosity increased, the tenacity of the side by side conjugate fibers increased, whereas the elongation decreased. ${ }^{3,7}$

To investigate the effect of viscosity on the properties of the conjugate fibers, the shrinkage ratio of fibers prepared under different experimental conditions was measured, and the results are shown in Figure 3. As can be seen in the figure, the conjugate fibers showed a high dry shrinkage ratio and a low wet shrinkage ratio compared with SD fibers.

Figure 4 shows the crimp ratio of side by side conjugate fibers prepared under different experimental conditions. The crimp ratio of the conjugate fibers was found to be lower than that of SD fiber. This is due to introduction of a ring structure in CHDM into the polymer chain.

Sea-island Conjugate Spinning. The sea-island type fibers show CHDM-modified Co-PET (island ingredient) distributed 


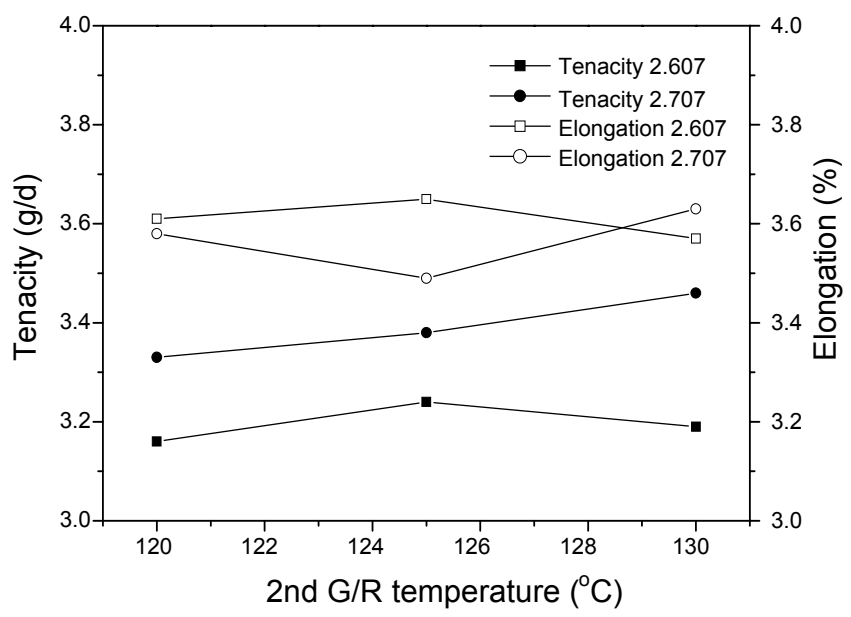

Figure 5. Effect of 2 nd G/R temperature on the tenacity and elongation for sea-island type conjugate fibers.

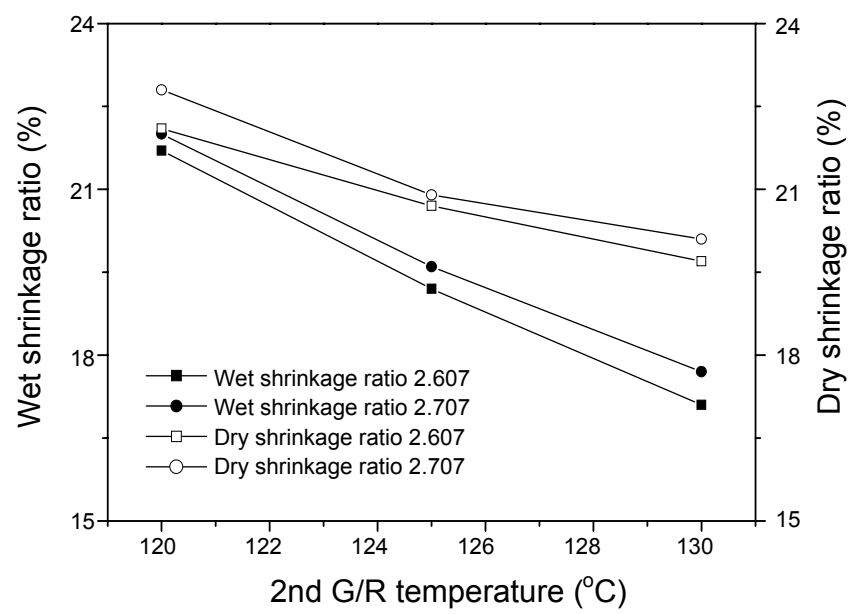

Figure 6. Effect of 2 nd G/R temperature on the wet shrinkage ratio and dry shrinkage ratio for sea-island type conjugate fibers.

in sea ingredient at the fiber section. To study characteristics of sea-island conjugate fibers, the tenacity and elongation were measured at a $1 \mathrm{st} \mathrm{G} / \mathrm{R}$ temperature of $95^{\circ} \mathrm{C}$ and $2 \mathrm{nd} \mathrm{G} / \mathrm{R}$ speed of $4250 \mathrm{~m} / \mathrm{min}$, and the results are shown in Figure 5. The results indicate that the drawing ratio and $2 \mathrm{nd} \mathrm{G} / \mathrm{R}$ temperature did not significantly affect the physical properties, i.e. tenacity and elongation. $^{7}$

Figure 6 shows the effect of 2 nd G/R temperature on the wet shrinkage ratio and dry shrinkage ratio for the sea-island type conjugate fibers. Both the wet shrinkage ratio and dry shrinkage ratio of the conjugate fibers decreased with increasing 2nd G/R temperature.

Figures 7 and 8 show the effects of 1 st G/R and 2 nd G/R temperatures on the physical properties and shrinkage ratio for sea-island type conjugate fibers. As shown here, the physical properties of the fibers did not show a clear tendency with different 1 st G/R temperature. In contrast, when the 2 nd G/R temperature was increased, the tendency of the fibers incresed and the elongation of the fibers decreased. The wet shrinkage ratio and dry shrinkage ratio of the conjugate fibers decreased (a)

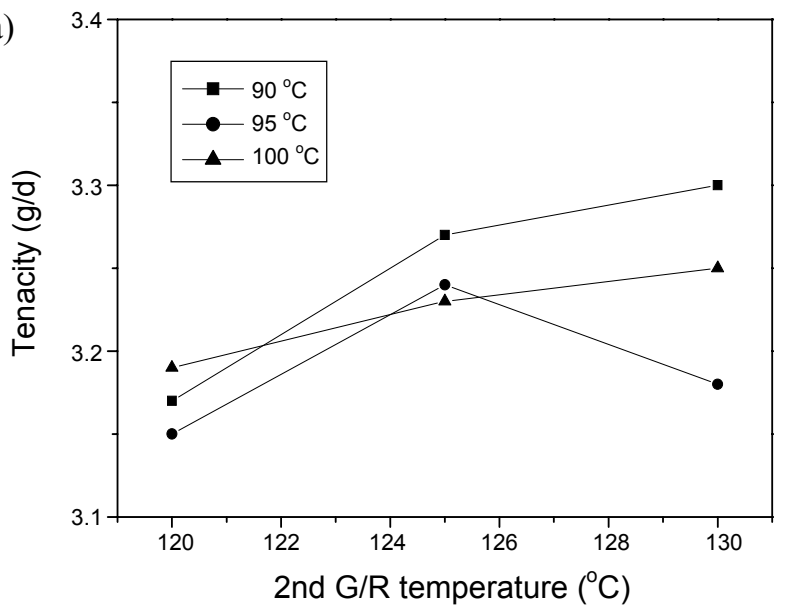

(b)

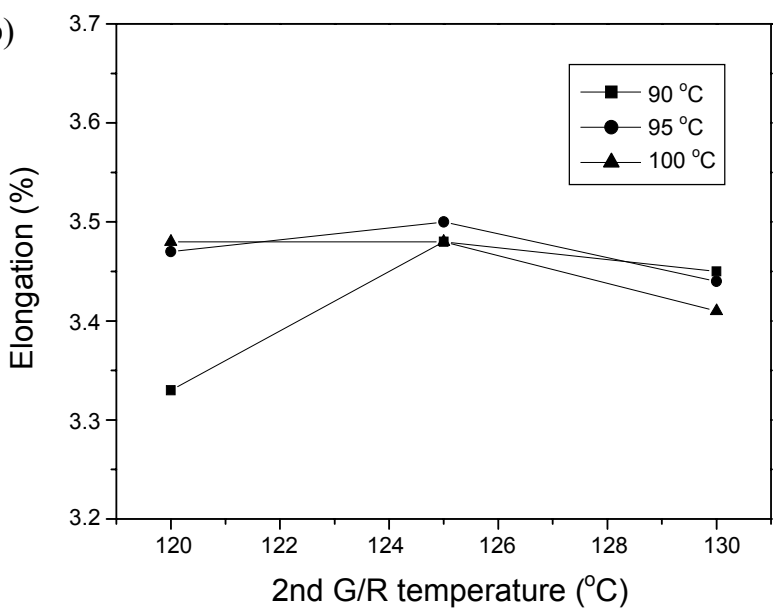

Figure 7. Effect of 1 st $\mathrm{G} / \mathrm{R}$ and 2 nd G/R temperature on the tenacity (a) and elongation (b) for sea-island type conjugate fibers.

with increasing 2 nd G/R temperature, as shown in Figure 8.

Figure 9 shows the weight loss of regular PET fiber and CoPET fiber at different reduction times. The weight loss curve can be divided into two stages. The first stage is characterized by high weight loss, from 0 to $30 \mathrm{~min}$. The second stage, above this time, features low weight loss. The Co-PET fiber showed higher weight loss than that of regular PET fiber produced under the same conditions.

Figure 10 shows the K/S values of regular PET fiber and 5\% CHDM-containing Co-PET fiber with different dyeing temperatures. As can be seen here, the K/S value of Co-PET fiber is lower than that of regular PET fiber under the same conditions. $^{11}$

Split Type Conjugate Spinning. Split type conjugate fibers were prepared according to the experimental condictions listed in Table 3. The properties of the split type conjugate fibers were measured, and the results are shown in Table 3.

In order to examine the heat shrinkage during fiber processing, the shrinkage in the length and width directions before and after calendering was measured. The dry shrinkage of nonwoven as a function of temperature before and after calendering is shown in Figure 11. The dry shrinkage of the nonwoven before calendering is higher than that of the nonwoven after calender- 
(a)

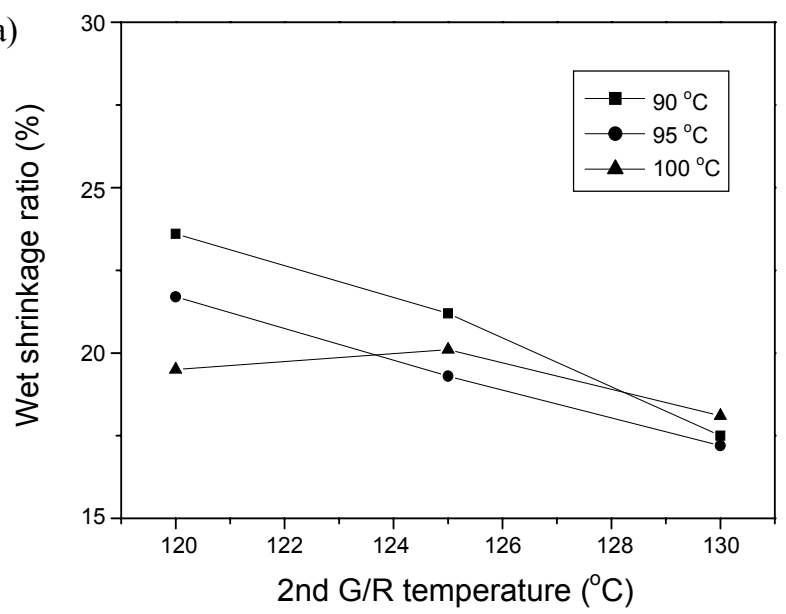

(b)

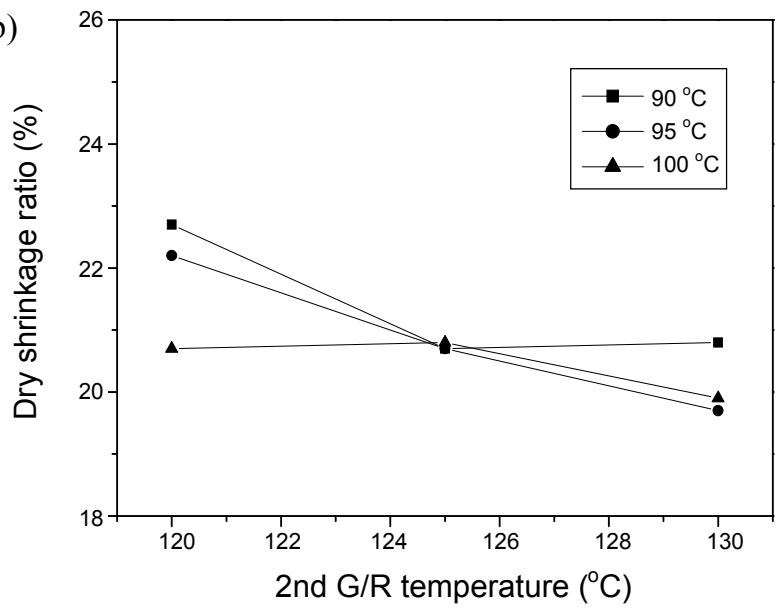

Figure 8. Effect of 2 nd $\mathrm{G} / \mathrm{R}$ temperature on the wet shrinkage ratio (a) and dry shrinkage ratio (b) for sea-island type conjugate fibers.

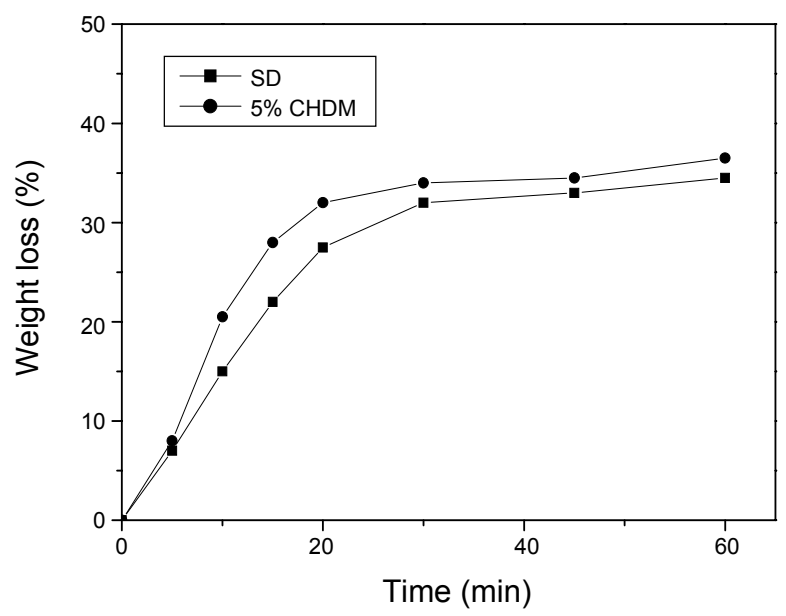

Figure 9. Comparison of weight loss of regular PET and Co-PET at different reduction times.

ing at a temperature range of $80-180{ }^{\circ} \mathrm{C}$.

Weight loss experiments were performed at $180{ }^{\circ} \mathrm{C}$ and $3 \%$ $\mathrm{NaOH}$ solution, and the weight loss was measured at 5 minute intervals. Figure 12 shows the weight loss behavior of a nonwoven prepared from orange spilt type conjugate fibers. The

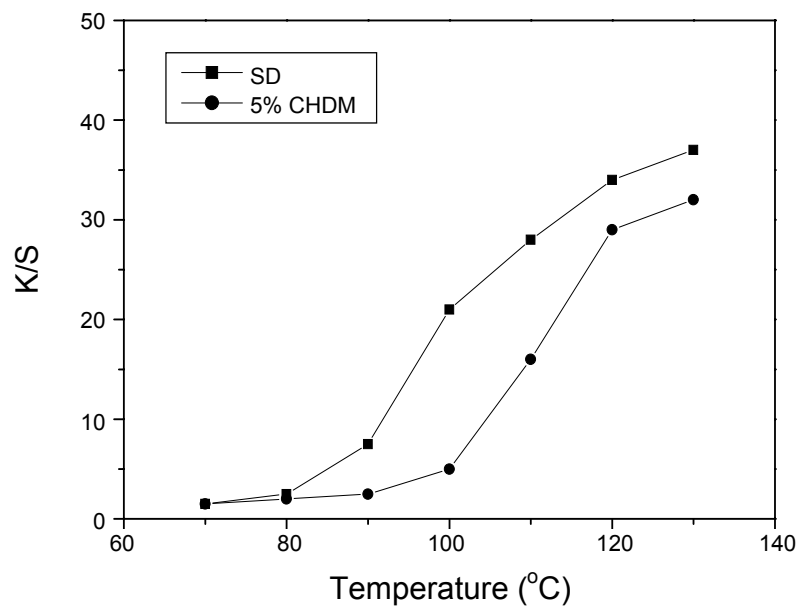

Figure 10. Comparison of K/S values of regular PET and Co-PET with 5\% CHDM in different dyeing temperatures.

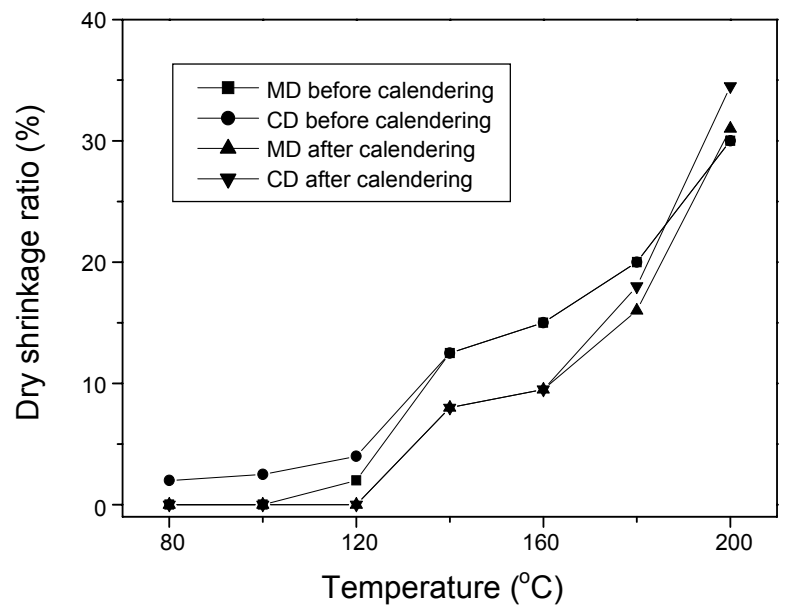

Figure 11. Dry shrinkage ratio of nonwoven as a function of temperature before and after calendering.

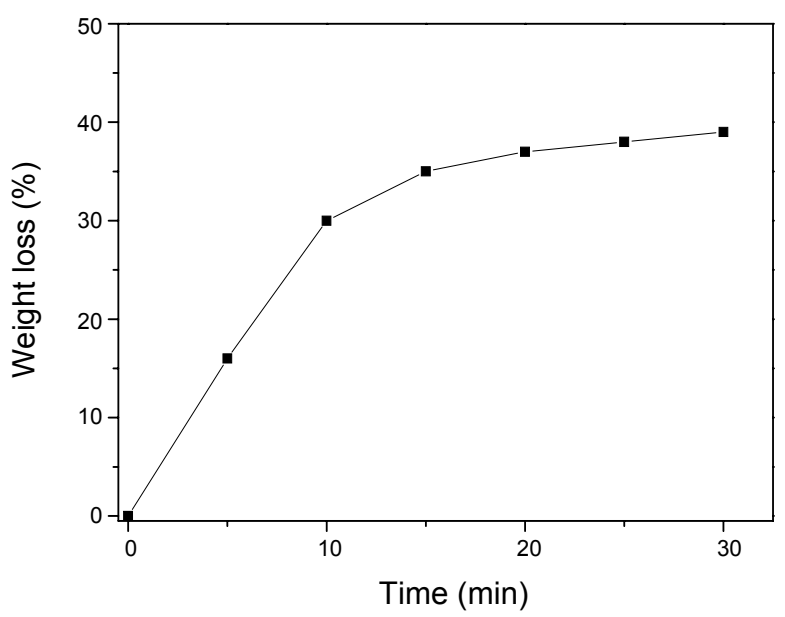

Figure 12. Weight loss behavior of nonwoven prepared from orange spilt type conjugate fibers.

weight loss of the fibers increased with increasing time. After $10 \mathrm{~min}$, the theoretical weight loss $(30 \%)$ was achieved. 


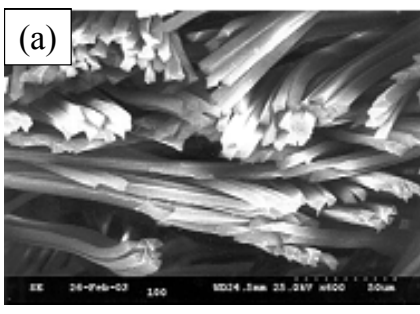

$100{ }^{\circ} \mathrm{C}$

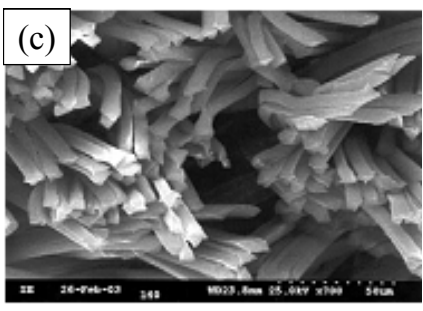

$140{ }^{\circ} \mathrm{C}$

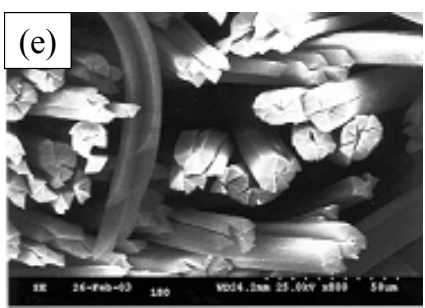

$180^{\circ} \mathrm{C}$

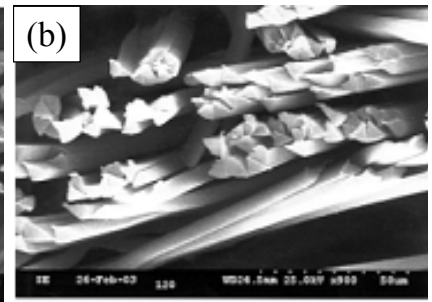

$120^{\circ} \mathrm{C}$

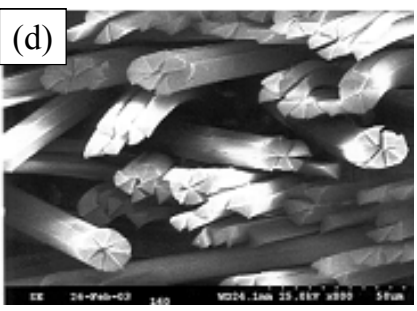

$160^{\circ} \mathrm{C}$

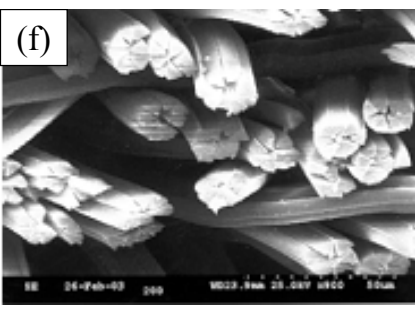

$200{ }^{\circ} \mathrm{C}$

Figure 13. SEM images of spilt behaviors as a function of temperature in orange type spilt conjugate fibers.

SEM images displaying spilt behaviors as a function of temperature in orange type spilt conjugate fibers are shown in Figure 13. As can be seen in the figure, the orange type spilt was easily produced at a temperature range of $120-140{ }^{\circ} \mathrm{C} .{ }^{12}$

\section{Conclusions}

Conjugate fibers were prepared from Co-PET resin using three spinning methods, and the properties of the fibers were

investigated using several techniques. The tenacity of side by side conjugate fibers was increased and the elongation was decreased when viscosity was increased. The tenacity and elongation of sea-island conjugate fibers were significantly affected by the drawing ratio and $2 \mathrm{nd} \mathrm{G} / \mathrm{R}$ temperature. The sea-island conjugate fibers showed a lower weight reduction ratio and a lower $\mathrm{K} / \mathrm{S}$ value as compared to regular PET fabricated under the same conditions. The weight loss of orange spilt type conjugate fibers increased with increasing time and the theoretical weight loss was achieved at $10 \mathrm{~min}$. The SEM results indicated that orange type spilt was readidy produced at a temperature range of $80-180{ }^{\circ} \mathrm{C}$.

Acknowledgments. This research was supported by a grant from the Fundamental R\&D Program for Core Technology of Materials, funded by the Ministry of Knowledge Economy, Republic of Korea.

\section{References}

1. Whinfield, J. R. Nature 1946, 158, 930.

2. Carothers, W. H. Collected Papers Interscience; New York, 1940.

3. Wu, G.; Li, Q.; Cuculo, J. A. Polymer 2000, 41, 8139.

4. (a) Kim, J. Y.; Kim, S. H.; Kikutani, T. J. Polym. Sci. B: Polym. Phys. 2004, 42, 1218. (b) Shin, C. H.; Seo, J, M.; Bae, J. S. J. Ind. Eng. Chem. 2009, 11, 748.

5. (a) Mohn, R. N.; Paul, E. R.; Barlow J. W.; Cruz, C. A. J. Appl. Polym. Sci. 1979, 23, 575. (b) Im, J. S.; Jang, J. S.; Lee, Y. S. J. Ind. Eng. Chem. 2009, 15. 914.

6. Smith, W. A.; Barlow, J. W.; Paul, E. R. J. Appl. Polym. Sci. 1981, 26,4233 .

7. Grasser, W.; Schmidt, H. W.; Giesa, R. Polymer 2001, $42,8517$.

8. Needles, H. L.; Holmes, S.; Park, M. J. J. Soc. Dyers Color. 1990, 106, 385.

9. Bang, H. J.; Kim, H. Y.; Jin, F. L.; Park, S. J. Bull. Korean Chem. Soc. submitted for publication.

10. Delpech, M. C.; Coutinho, F. M. B.; Habibe, M. E. S. Polym. Test. 2002, $21,411$.

11. Lin, C. J.; Wang, Y. C.; Lin, L. D.; Chiou, C. R.; Wang, Y. N.; Tsai, M. J. J. Mater. Process. Tech. 2008, 198, 419.

12. Jin, F. L.; Park, S. J. Bull. Korean Chem. Soc. 2008, 29, 2521. 